Provided for non-commercial research and education use. Not for reproduction, distribution or commercial use.

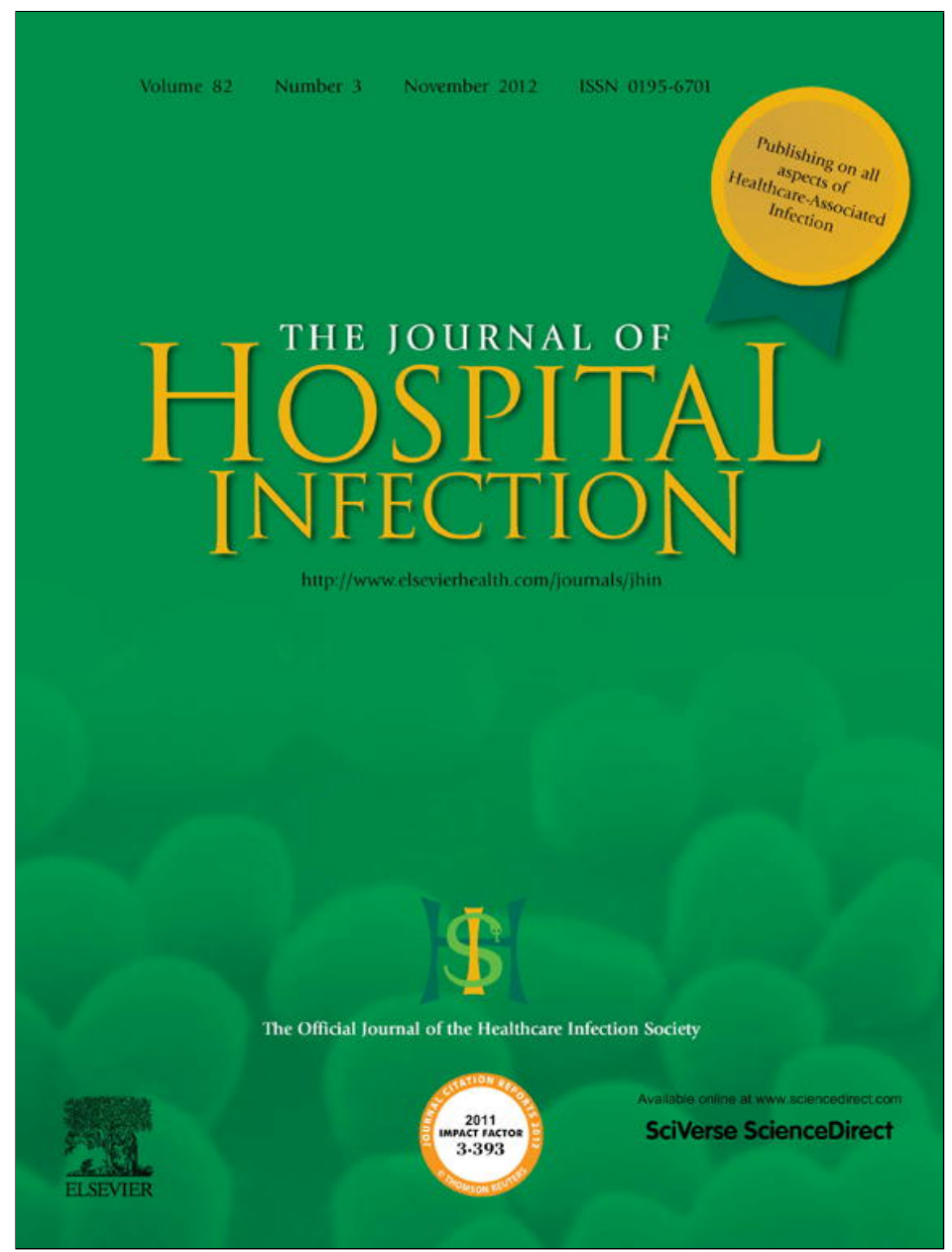

This article appeared in a journal published by Elsevier. The attached copy is furnished to the author for internal non-commercial research and education use, including for instruction at the authors institution and sharing with colleagues.

Other uses, including reproduction and distribution, or selling or licensing copies, or posting to personal, institutional or third party websites are prohibited.

In most cases authors are permitted to post their version of the article (e.g. in Word or Tex form) to their personal website or institutional repository. Authors requiring further information regarding Elsevier's archiving and manuscript policies are encouraged to visit:

http://www.elsevier.com/copyright 


\title{
Results from the second Scottish national prevalence survey: the changing epidemiology of healthcare- associated infection in Scotland
}

\author{
J. Reilly ${ }^{a}$, S. Cairns ${ }^{a, *}$, S. Fleming ${ }^{a}$, D. Hewitt ${ }^{b}$, R. Lawder ${ }^{b}$, \\ C. Robertson ${ }^{a, b, c, d}$, W. Malcolm ${ }^{a}$, D. Nathwani ${ }^{\text {e }}$, C. Williams ${ }^{f}$ \\ ${ }^{\mathrm{a}}$ Health Protection Scotland, Glasgow, UK \\ ${ }^{\mathrm{b}}$ Information Services Division, Edinburgh, UK \\ cMathematics and Statistics, Strathclyde University, Glasgow, UK \\ dInternational Prevention Research Institute, Lyon, France \\ e NHS Tayside, Ninewells Hospital and Medical School, Dundee, UK \\ ${ }^{\mathrm{f}}$ NHS Greater Glasgow and Clyde, UK
}

\section{A R T I C L E I N F O}

\section{Article history:}

Received 28 May 2012

Accepted 30 July 2012

Available online 28 September

2012

\section{Keywords:}

Epidemiology

Healthcare-associated infection

Infection prevention and

control

Point prevalence surveys

\begin{abstract}
$S U M M A R Y$
Background: Healthcare-associated infections (HAIs) are a recognized public health problem worldwide. Point prevalence surveys (PPSs) can be used to measure the burden of all HAl types.

Aim: To measure the prevalence of $\mathrm{HAl}$ and determine any changes in the epidemiology of HAl since the first Scottish national PPS.

Methods: A national rolling PPS in National Health Service (NHS) acute, NHS non-acute, NHS paediatric and independent hospitals was carried out during September and October 2011 using the European Centre for Disease Prevention and Control protocol designed for the European PPS. The prevalence of HAI and distribution of HAI types were measured and the results compared with the first Scottish national HAI point prevalence survey of 2005/2006.

Results: The prevalence of HAl was $4.9 \%, 2.5 \%, 6.1 \%$ and $1.2 \%$ in acute, non-acute, paediatric and independent hospitals respectively. The prevalence of HAl was significantly higher in acute hospitals compared with non-acute hospitals. There were no significant differences between the prevalence in the other hospital types. The prevalence of $\mathrm{HAl}$ in acute and non-acute hospitals was lower than the first survey by approximately one-third. The proportion of HAls that were urinary tract infection, surgical site infection and bloodstream infection was higher and the proportion that were gastrointestinal including Clostridium difficile infection was lower in acute hospitals compared with the previous survey.
\end{abstract}

\footnotetext{
* Corresponding author. Address: Health Protection Scotland, Meridian Court, 5 Cadogan Street, Glasgow G2 6QE, UK. Tel.: +44 0141 2822921.

E-mail address: shona.cairns@nhs.net (S. Cairns).
} 
Conclusions: The epidemiology of $\mathrm{HAl}$ has changed in Scotland since the first national survey in 2005/2006, thus infection prevention and control measures require to be refocused in this regard. The lower prevalence and changing epidemiology of $\mathrm{HAl}$ in acute and non-acute care suggest that there may be a temporal relationship with the implementation of the national programme of targeted HAI interventions in the intervening period.

(c) 2012 The Healthcare Infection Society. Published by Elsevier Ltd. All rights reserved.

\section{Introduction}

Healthcare-associated infections (HAls) are a recognized public health problem worldwide and contribute significantly to morbidity and mortality in the hospital population. ${ }^{1}$ The additional costs arising from treatment of HAl place a significant burden on healthcare resources. Multiple factors contribute to the increasing risk of $\mathrm{HAl}$, including an ageing population, widespread use of complex therapeutic interventions, and emerging and re-emerging antimicrobial resistant micro-organisms. ${ }^{2,3}$

Point prevalence surveys (PPSs) are a useful tool to measure and monitor the burden of HAI. ${ }^{4}$ They are less resource intensive relative to measuring the incidence of an outcome in which patients are followed up over time, and can be used to describe the burden of all HAl types on health services including those not routinely monitored. ${ }^{5}$

The first Scottish National HAl Prevalence Survey was carried out by Health Protection Scotland (HPS) between October 2005 and October 2006 and included all acute hospitals and a $25 \%$ sample of non-acute hospitals. ${ }^{6}$ The survey reported that 9.5\% [95\% confidence interval $(\mathrm{Cl}): 8.8-10.2]$ and $7.3 \%$ (95\% Cl: $6.0-8.6)$ of patients in acute and non-acute hospitals, respectively, had HAls at the time of survey.

The results from the Scottish survey provided the Ministerial HAI Task Force (HAITF), led by the Chief Nursing Officer with an estimate of the burden of $\mathrm{HAl}$ in Scottish hospitals and informed the development of targeted incidence surveillance programmes such as surveillance of central vascular catheterrelated infections and catheter-associated urinary tract infections, interventions to reduce $\mathrm{HAl}$, infection prevention and control (IPC) guidance and quality improvement tools.

A second survey was commissioned by the Scottish Government for completion in March 2012. This second survey was considered important because of the dynamic nature of healthcare delivery, the changing nature of the population receiving hospital care, the evolution of micro-organisms, as well as changing healthcare interventions and the infection risks therein.

The European Centre for Disease Prevention and Control (ECDC) requested that all member states carry out a PPS using a standardized protocol by June 2012. The use of a standardized EU protocol will allow benchmarking of prevalence between European countries using a consistent approach. For this reason and to enable Scotland to contribute to the European PPS and the strategy to reduce $\mathrm{HAl}$ and antimicrobial resistance, the ECDC protocol was adopted for use in the Scottish national PPS. ${ }^{7}$ Furthermore, the protocol was extended to enable comparison with the first survey carried out in 2005/2006 using a different protocol and to address national HAl policy questions.

The aims of the survey were to take stock of the current epidemiology, review any changes in epidemiology which have occurred since 2005/2006 by comparison of the two surveys, inform the development of future interventions, target future incidence surveillance, and to prioritize interventions to reduce the risk of infection in healthcare.

\section{Methods}

\section{Study design}

A rolling PPS was carried out in Scottish hospitals in September and October 2011. The patient-based ECDC protocol for PPS was adopted. ${ }^{8}$

The survey included all National Health Service (NHS) acute, NHS paediatric and independent hospitals, and, in an extension of the ECDC protocol, a $25 \%$ sample of NHS non-acute hospitals was selected using a stratified cluster sample carried out following calculations to determine the necessary sample size. The non-acute hospitals category included hospitals for longterm care of the elderly, psychiatric hospitals and long-term rehabilitation hospitals.

Data were collected by a collaborative team of staff members from local infection prevention and control, and by antimicrobial management teams. A one-day training course was developed using standardized ECDC training materials and was delivered to a total of 171 staff across Scotland.

Data were extracted from all available sources on the ward at the time of survey. Data collectors were advised to seek clarification from ward staff if the information held in the records was not clear.

Full details of the study design and data collection methods are provided in the PPS protocol. ${ }^{9}$

\section{HAl case definitions}

HAl data were collected for patients with an active HAl at the time of survey. The ECDC case definitions for HAl were used. $^{8}$

\section{Analysis}

Descriptive analyses were carried out using SPSS Version $17^{\circledR}$ and Stata Version $9^{\circledR}$. The survey was analysed as a cluster sample with wards nested within hospitals. For the non-acute hospitals sampling weights were calculated to reflect the slightly differential number of hospitals selected from the boards. The prevalence of HAl was calculated with $95 \% \mathrm{Cls}$ using exact binomial methods for small samples and Wilson's method, adjusted for the clustering of wards within hospitals.

In order to make a valid comparison between the 2005/2006 survey and the 2011 survey in acute and non-acute hospitals, an adjustment was undertaken to account for differences in the study protocols and the included survey populations. In order to make a valid comparison, HAls identified during the 2005/ 
2006 survey that did not meet the case definition on the day of the survey were excluded, as were HAls present on admission to hospital with the exception of SSI, those originating in another hospital and those occurring in paediatric patients in the 2011 survey.

The $\mathrm{Cl}$ for the adjusted percentage change between the two surveys in acute hospitals was calculated using a bootstrap simulation (100,000 samples) using a normal approximation to the binomial. The design effects associated with clustering of patients in wards in the two surveys as well as the sampling error in the estimation of the ratio were taken into account. In the non-acute hospitals, it was necessary to compare specialtyadjusted prevalence due to differences in the distribution of specialties between the two surveys. The prevalence in 2011 was adjusted to the bed distribution in 2005/2006 and the $\mathrm{Cl}$ for the percentage change between the surveys was calculated using the same bootstrap simulation used for the acute hospitals. Full details are provided in the survey report. ${ }^{10}$

\section{Results}

A total of 13,558 patients in 75 hospitals in Scotland were included in the survey. All NHS acute $(N=42)$, NHS paediatric $(N=3)$ and independent hospitals $(N=7)$ and a $25 \%$ sample of non-acute hospitals $(N=23)$ in Scotland were included. The number of hospitals, wards, and patients surveyed is described by hospital type in Table I. The size of the hospitals ranged from five beds to 891 beds and the median number of beds was 108 [interquartile range (IQR): 35-355].

The median ages of patients aged $\geq 16$ years in acute and non-acute hospitals were 72 years (IQR: $55-81$ ) and 71 years (IQR: $49-83)$, respectively. Nearly $60 \%$ of patients in acute hospitals $(N=6902)$ and non-acute hospitals $(N=968)$ were aged $\geq 65$ years.

\section{Prevalence of $\mathrm{HAl}$}

The prevalence of HAl by hospital type is presented in Table II. The prevalence of HAl was significantly higher in acute hospitals compared with non-acute hospitals. There were no significant differences in HAl prevalence between the other hospital types.

The distribution of HAl types in the four hospital categories is described in Table III.

\section{Comparison with the first Scottish prevalence survey}

Adjusted analyses indicate that the prevalence of $\mathrm{HAl}$ in acute and non-acute hospitals was 33\% (95\% Cl: $24-41)$ and 32\%
Table II

Prevalence of healthcare-associated infection (HAI) by hospital category

\begin{tabular}{lcccl}
\hline $\begin{array}{l}\text { Hospital } \\
\text { type }\end{array}$ & $\begin{array}{c}\text { No. of } \\
\text { patients } \\
\text { surveyed }\end{array}$ & $\begin{array}{c}\text { No. of } \\
\text { patients } \\
\text { with HAl }\end{array}$ & $\begin{array}{c}\text { Prevalence } \\
(\%)\end{array}$ & $95 \% \mathrm{Cl}$ \\
\hline Acute & 11,525 & 559 & 4.9 & $4.4-5.4$ \\
Non-acute & 1647 & 41 & 2.5 & $1.6-3.6$ \\
Paediatric & 212 & 13 & 6.1 & $2.6-11.2$ \\
Independent & 84 & 1 & 1.2 & $0.4-6.3$ \\
\hline
\end{tabular}

$\mathrm{Cl}$, confidence interval.

HAl data were not recorded for 90 patients.

(95\% Cl: 9-50) lower than the HAl prevalence reported in 2005/ 2006, respectively.

The distribution of HAl types in acute hospitals in the first and second surveys is recorded in Table IV. The percentage of all HAls that were bloodstream infections (BSIs), pneumonia and urinary tract infections (UTIs) was higher, whereas the percentage of gastrointestinal (Gl) infections was lower in this survey compared with the first survey. The number of comparable HAls in non-acute hospitals was small $(N=33)$ so no further commentary is offered on changes in the distribution of HAls in these hospitals.

\section{Discussion}

Healthcare-associated infections are recognized as a public health threat, a patient safety risk issue and a cause for concern nationally and internationally. Although within the UK there has been a significant reduction in specifically targeted HAls, such as CDI and S. aureus bacteraemia over the last four years, the burden of all HAls is not routinely monitored. ${ }^{11,12}$ PPS studies provide the opportunity to take stock of the current epidemiology and to review any changes in epidemiology which have occurred. ${ }^{4}$ Intelligence from PPS can be used to inform the development of future interventions, target future incidence surveillance, and prioritize interventions to reduce the risk of infection in healthcare. ${ }^{13}$

The observed prevalence of HAl in Scottish acute hospitals was $4.9 \%$ (95\% Cl: 4.4-5.4) and in non-acute hospitals 2.5\% (95\% $\mathrm{Cl}: 1.6-3.6)$. The results from this national PPS are similar to those reported in other countries though there are major limitations with the differences in the patient population, case definitions and protocols used. ${ }^{14-17}$ The adoption of the ECDC PPS protocol for this survey and the completion of the EU PPS in all member states will enable robust benchmarking between European countries. Although adoption of the patient-based

Table I

Total number of patients, ward and hospitals surveyed, by hospital type

\begin{tabular}{|c|c|c|c|c|c|c|c|}
\hline Hospital type & $\begin{array}{c}\text { No. of } \\
\text { hospitals } \\
\text { surveyed }\end{array}$ & $\begin{array}{c}\text { No. of } \\
\text { wards } \\
\text { surveyed }\end{array}$ & $\begin{array}{l}\text { No. of } \\
\text { beds }\end{array}$ & $\begin{array}{l}\text { No. of } \\
\text { patients }\end{array}$ & $\begin{array}{l}\text { No. of } \\
\text { eligible } \\
\text { patients }\end{array}$ & $\begin{array}{c}\text { No. of } \\
\text { eligible patients } \\
\text { surveyed }\end{array}$ & $\begin{array}{c}\% \text { of eligible } \\
\text { patients surveyed }\end{array}$ \\
\hline NHS acute & 42 & 700 & 14,831 & 12,600 & 12,323 & 11,604 & 94.2 \\
\hline NHS non-acute & 23 & 110 & 2042 & 1678 & 1670 & 1656 & 99.2 \\
\hline NHS paediatric & 3 & 25 & 397 & 258 & 247 & 213 & 86.2 \\
\hline Independent & 7 & 9 & 173 & 93 & 86 & 85 & 98.8 \\
\hline Total & 75 & 844 & 17,443 & 14,629 & 14,326 & 13,558 & 94.6 \\
\hline
\end{tabular}

NHS, National Health Service. 
Table III

Number and percentage of different healthcare-associated infections (HAls) by hospital category

\begin{tabular}{|c|c|c|c|c|c|c|c|c|}
\hline \multirow[t]{3}{*}{ HAl types } & \multicolumn{8}{|c|}{ No. of HAls } \\
\hline & \multicolumn{2}{|c|}{ Acute } & \multicolumn{2}{|c|}{ Non-acute } & \multicolumn{2}{|c|}{ Paediatric } & \multicolumn{2}{|c|}{ Independent } \\
\hline & No. & $\%$ & No. & $\%$ & No. & $\%$ & No. & $\%$ \\
\hline Bone/joint infection & 3 & 0.5 & 0 & 0 & 0 & 0 & 0 & 0 \\
\hline Cardiovascular system infection & 1 & 0.2 & 0 & 0 & 0 & 0 & 0 & 0 \\
\hline Central nervous system infection & 4 & 0.7 & 0 & 0 & 1 & 7.1 & 0 & 0 \\
\hline CVC/PVC-related infection & 16 & 2.7 & 0 & 0 & 0 & 0 & 0 & 0 \\
\hline Eye, ear, nose, throat and mouth infection & 55 & 9.2 & 7 & 17.1 & 2 & 14.3 & 0 & 0 \\
\hline Gastrointestinal tract infection & 41 & 6.8 & 5 & 12.2 & 1 & 7.1 & 0 & 0 \\
\hline Laboratory-confirmed BSI & 57 & 9.5 & 3 & 7.3 & 3 & 21.4 & 0 & 0 \\
\hline Lower respiratory tract infection, other than pneumonia & 17 & 2.8 & 1 & 2.4 & 0 & 0.0 & 0 & 0 \\
\hline Neonatal infection & 7 & 1.2 & 0 & 0 & 2 & 14.3 & 0 & 0 \\
\hline Pneumonia & 105 & 17.5 & 4 & 9.8 & 1 & 7.1 & 0 & 0 \\
\hline Reproductive tract infection & 3 & 0.5 & 1 & 2.4 & 0 & 0 & 0 & 0 \\
\hline Skin and soft tissue & 24 & 4.0 & 4 & 9.8 & 0 & 0 & 0 & 0 \\
\hline Surgical site infection & 112 & 18.6 & 0 & 0 & 1 & 7.1 & 1 & 100.0 \\
\hline Systemic infection & 20 & 3.3 & 0 & 0 & 1 & 7.1 & 0 & 0 \\
\hline Urinary tract infection & 136 & 22.6 & 16 & 39.0 & 2 & 14.3 & 0 & 0 \\
\hline Total & 601 & 100 & 41 & 100 & 14 & 100 & 1 & 100 \\
\hline
\end{tabular}

CVC/PVC, central venous catheter/peripheral venous catheter; BSI, bloodstream infection.

ECDC protocol resulted in very resource-intensive data collection, it provided a full dataset for all patients. This enabled us to control for confounders such as patient case-mix, inclusive of underlying medical condition of the patient, and for benchmarking between Scottish hospitals to be carried out. Results from the pilot of the EU PPS indicate that the prevalence reported in the volunteer pilot hospitals was $7.1 \%(95 \% \mathrm{Cl}$ : 6.7-7.5), with which the Scottish mean prevalence compares favourably. ${ }^{18}$ The prevalence was significantly higher in acute hospitals compared that in non-acute hospitals. However, the large number of younger psychiatric patients included in the non-

Table IV

Number and percentage of different healthcare-associated infections (HAls) in the 2005/2006 and 2011 surveys

\begin{tabular}{|c|c|c|c|c|}
\hline \multirow[t]{2}{*}{ HAl group } & \multicolumn{2}{|c|}{$\begin{array}{c}2005 / 2006 \\
\text { survey }\end{array}$} & \multicolumn{2}{|c|}{$\begin{array}{l}2011 \\
\text { survey }\end{array}$} \\
\hline & No. & $\%$ & No. & $\%$ \\
\hline Urinary tract infection & 130 & 15.6 & 117 & 23.8 \\
\hline Surgical site infection & 179 & 21.4 & 92 & 18.7 \\
\hline Pneumonia & 78 & 9.3 & 89 & 18.1 \\
\hline Bloodstream infection & 32 & 3.8 & 52 & 10.6 \\
\hline $\begin{array}{l}\text { Eye, ear, nose, throat } \\
\text { or mouth infection }\end{array}$ & 114 & 13.6 & 49 & 10.0 \\
\hline Gastrointestinal infection & 168 & 20.1 & 28 & 5.7 \\
\hline Skin and soft tissue infection & 81 & 9.7 & 18 & 3.7 \\
\hline $\begin{array}{l}\text { Lower respiratory infection } \\
\text { other than pneumonia }\end{array}$ & 19 & 2.3 & 17 & 3.5 \\
\hline Systemic infection & 12 & 1.4 & 16 & 3.3 \\
\hline Cardiovascular system infection & 4 & 0.5 & 6 & 1.2 \\
\hline Reproductive system infection & 11 & 1.3 & 3 & 0.6 \\
\hline $\begin{array}{l}\text { Central nervous system } \\
\text { infection }\end{array}$ & 2 & 0.2 & 3 & 0.6 \\
\hline Bone and joint infection & 6 & 0.7 & 2 & 0.4 \\
\hline Total & 836 & 100 & 492 & 100 \\
\hline
\end{tabular}

acute hospital population sample may account for this difference. Comparisons of HAl prevalence in non-acute care excluding psychiatric patients indicated a prevalence of $5.0 \%$ (95\% Cl: 2.6-7.4); this was not significantly different from acute care. The prevalence of $\mathrm{HAl}$ in paediatric and independent hospitals was described for the first time and was $6.1 \%(95 \% \mathrm{Cl}$ : 2.6-11.2) and 1.2\% (95\% Cl: 0.4-6.3), respectively.

The distribution of HAl types differed between the types of hospital surveyed and was relative to the population at risk within those settings. UTIs placed a significant burden on both acute and non-acute hospitals. Surgical site infections and pneumonia were more frequent in acute hospitals and GI infections were more frequent in non-acute hospitals. BSIs and clinical sepsis were the most frequently occurring HAls in paediatric hospitals, accounting for more than a third $(N=5)$, although overall the number of HAls in this setting was small. The number of infections in the independent sector were so few $(N=1)$ that no further commentary is offered on this. It is important to note that the prevalence of HAl within the independent hospitals was not significantly lower than in NHS acute hospitals.

The prevalence of $\mathrm{HAl}$ overall in acute and non-acute hospitals was lower than that reported in the first Scottish national HAl prevalence survey carried out in 2005/2006. ${ }^{6}$ While there are definitional issues with comparison of the two surveys, after adjustment for differences in the survey population and protocol, the results indicate that the prevalence of HAl was lower than previously reported, by approximately one-third. This finding is consistent with the significant reductions in the mandatory incidence data reported to date in Scotland and suggests an association with the implementation of national policy initiatives such as a hand hygiene campaign and development of standard infection prevention and control precautions policies in the intervening period. Compliance with the World Health Organization 'Five Moments' for hand hygiene has increased from 64\% to 95\% between 2007 and 2011 in Scotland. ${ }^{12}$ A temporal relationship between the implementation of national initiatives and a significant reduction in the 
incidence of Staphylococcus aureus BSI and Clostridium difficile infection (CDI) has previously been reported in England. ${ }^{19}$

The epidemiology of HAl and the distribution of HAl types have changed since the first survey. These changes must be considered when setting local and national IPC priorities. After adjusting for differences in the survey protocols, the proportions of all HAls that were UTIs, surgical site infections (SSI) and BSIs in acute hospitals were higher than in the first survey, whereas the proportion of GI infections was lower.

In this most recent PPS, UTIs were the most common infection type in both acute and non-acute hospitals and were the leading source of secondary BSIs where the source could be determined. This is an area to date with little focus in patient safety programmes and should be considered for future priority given the preventable nature of UTI associated with catheter use. ${ }^{20}$ There is a continuing burden of SSI in the acute inpatient population. This PPS identified SSI following orthopaedic surgery as the most common type of SSI in the inpatient population. The incidence of SSI following hip arthroplasty surgery has fallen significantly since 2003 but has remained stable for the last three years of reporting and consideration for whether the irreducible minimum has been reached is required. ${ }^{21,22}$ The higher proportion of $\mathrm{BSI}$ in acute hospitals may reflect the underlying medical conditions of the hospital population and the increasing complexity of care during inpatient stays. Onethird of all BSIs were of unknown origin at the time of survey indicating the complexity in identifying IPC interventions to reduce these sources of infection and indicating the need for enhanced surveillance to better describe the causes. The lower proportion of gastrointestinal infections reflects the decreasing incidence of CDI in the Scottish hospital population following the implementation of a number of national policy interventions focused on infection prevention and control and antimicrobial stewardship.

Several limitations to prevalence surveys are important to note for the purposes of interpretation of this paper including: methodological issues concerning cross-sectional data, interrater reliability with respect to $\mathrm{HAl}$ definitions, microbiology availability and seasonality. In addition, comparisons with previous surveys are limited by changes in hospital population demographics and practices over time.

The results of this PPS indicate that HAl is lower in acute and non-acute care than the last survey, and the lower prevalence and changing epidemiology of HAl in acute and non-acute care suggest a temporal relationship with the implementation of the national programme of targeted $\mathrm{HAl}$ interventions in the intervening period. This first description of HAI in paediatrics and independent hospitals has identified where potential future IPC measures should be targeted.

\section{Acknowledgements}

We thank the infection control and antimicrobial management teams in all of the participating hospitals for their cooperation and support.

\section{Conflict of interest statement}

None declared.

\section{Funding source}

This project was funded by the Scottish Government Health and Social Care Directorate HAI Task Force.

\section{References}

1. World Health Organization. Report on the burden of endemic health care-associated infection worldwide. Geneva: WHO; 2011.

2. Strausbaugh LJ. Emerging health care-associated infections in the geriatric population. Emerg Infect Dis 2001;7:268-271.

3. European Centre for Disease Prevention and Control. Antimicrobial resistance surveillance in Europe 2010. Annual report of the European Antimicrobial Resistance Surveillance Network (EARSNet). Stockholm: ECDC; 2011.

4. French GL, Cheng AF, Wong SL, Donnan S. Repeated prevalence surveys for monitoring effectiveness of hospital infection control. Lancet 1989;2:1021-1023.

5. Brusaferro S, Regattin L, Faruzzo A, et al. Surveillance of hospitalacquired infections: a model for settings with resource constraints. Am J Infect Control 2006;34:362-366.

6. Reilly J, Stewart S, Allardice GA, et al. Results from the Scottish National HAI Prevalence Survey. J Hosp Infect 2008;69:62-68.

7. European Centre for Disease Prevention and Control. ECDC Strategies for Disease Specific Programmes 2010-2013. Stockholm: ECDC; 2010.

8. European Centre for Disease Prevention and Control. Point prevalence survey of healthcare-associated infections and antimicrobial using in European acute care hospitals protocol. Version 4.2. Stockholm: ECDC; 2011.

9. Health Protection Scotland. Protocol for NHS Scotland national HAl prevalence survey. HPS; 2005.

10. Health Protection Scotland. Scottish National Point Prevalence Survey of Healthcare Associated Infection and Antimicrobial Prescribing 2011. Glasgow: Health Protection Scotland; 2012.

11. Health Protection Agency. Quarterly analyses: mandatory MRSA, MSSA and E. coli bacteraemia and CDI in England (up to October-December 2011). London: Health Protection Agency; 2012.

12. Health Protection Scotland. The annual surveillance of healthcare associated infections report January-December 2011. Glasgow: Health Protection Scotland; 2012.

13. Reilly J, Stewart S, Allardice G, Cairns S, Ritchie L, Bruce J. Evidence-based infection control planning based on national healthcare-associated infection prevalence data. Infect Control Hosp Epidemiol 2009;30:187-189.

14. van der Kooi TI, Mannien J, Wille JC, van Benthem BH. Prevalence of nosocomial infections in The Netherlands, 2007-2008: results of the first four national studies. J Hosp Infect 2010;75:168-172.

15. Gordts B, Vrijens F, Hulstaert F, Devriese S, Van de Sande S. The 2007 Belgian national prevalence survey for hospital-acquired infections. J Hosp Infect 2010;75:163-167.

16. Klavs I, Bufon Luznik T, Skerl M, et al. Prevalance of and risk factors for hospital-acquired infections in Slovenia - results of the first national survey, 2001. J Hosp Infect 2003;54:149-157.

17. Gastmeier P, Kampf G, Wischnewski N, et al. Prevalence of nosocomial infections in representative German hospitals. $J$ Hosp Infect 1998;38:37-49.

18. Zarb P, Coignard B, Griskeviciene J, et al. The European Centre for Disease Prevention and Control (ECDC) Pilot Point-Prevalence Survey of healthcare associated infections and antimicrobial use. In press.

19. Stone SP, Fuller C, Savage J, et al. Evaluation of the national Cleanyourhands campaign to reduce Staphylococcus aureus bacteraemia and Clostridium difficile infection in hospitals in England and Wales by improved hand hygiene: four year, prospective, ecological, interrupted time series study. BMJ 2012;344:e3005.

20. Harbarth S, Sax H, Gastmeier P. The preventable proportion of nosocomial infections: an overview of published reports. $J$ Hosp Infect 2003;54:258-266.

21. Health Protection Scotland. Surveillance of surgical site infection annual report. For procedures carried out from 1 January 2003 31 December 2010. Glasgow: HPS; 2011.

22. Ayliffe GA. Nosocomial infection - the irreducible minimum. Infect Control 1986;7:92-95. 